\title{
Assessment of Genetic Variability and Population Structure of Five Rabbit Breeds by Microsatellites Markers Associated with Genes
}

\author{
Tarik S.K.M. Rabie \\ Department of Animal Production, Faculty of Agriculture, Suez Canal University. Ismailia, 41522. Egypt. \\ *Corresponding author's e-mail: Tarik.rabie@agr.suez.edu.eg; ORCID: 0000-0001-9678-2323
}

Received: 22 Feb. 2020

Accepted: 26 Mar. 2020

\begin{abstract}
The present study was intended to estimate the specific genetic variants by using nine genetic markers among five rabbit breeds (New Zealand White, California, Chinchilla, Flander, and Babion) in Egypt. A total of 128 animals were used (19-35 rabbits per breed). A total of 97 alleles were detected across the breeds and the average number of alleles per locus was 2.16 \pm 0.11 . Five private alleles were present in Babion breed, where the locus INRACCDDV0023 had two private alleles of 293 and 297 base pairs with allele frequencies of 0.4 and 0.1 , respectively. The INRACCDDV0036, INRACCDDV0304, and INRACCDDV0241 loci had private allele for each (185bp (freq: 0.24), 197 (freq: 0.47), and 137bp (freq: 0.26), respectively). The mean of $H_{e}$ values ranged from $0.35 \pm 0.06$ to $0.49 \pm 0.07$. The average of the polymorphic information content was 0.41 (ranged from 0.298 at INRACCDDV0211 to 0.599 at INRACCDDV0036 locus). To estimate the genetic deviation of the five rabbit breeds, two parameters were evaluated: genetic differentiation $\left(F_{S T}\right)$, and genetic distance. The $F_{S T}$ values varied from 0.029 (INRACCDDV0036) to 0.785 (INRACCDDV0022). The similarity matrix showed that the Chinchilla breed was distinct from other breeds. In addition, among the nine loci, the Hardy-Weinberg equilibrium was highly significant for five loci. Therefore, the rabbit breeds are good reservoirs of allelic diversity that is the major basis for genetic improvement. Consequently, the breeders need a formal conservation plan for such breeds that are in danger of extinction in near future.

Key words: Genetic diversity, Microsatellite marker, Production performance, Rabbits
\end{abstract}

\section{INTRODUCTION}

Rabbits are phylogenetically closer to humans than to rodents. The rabbits' genetic map is still very limited to only one partial map (Korstanje et al., 2001, 2003). During the last 20 years, only markers detectable by conventional biochemical, immunological, and morphological methods have been used for linkage studies in the rabbit (Korstanje, 2000). Moreover, information about genetic variation help to design successful methodologies for the protection and restoration of natural populations. Previously, few efforts were initiated to conserve the available superior germplasm of the rabbits in Egypt (Grimal et al., 2012; Rabie, 2012; El-Aksher et al., 2017; Badr et al., 2016). The discovery of microsatellites in transcripts and regulatory districts of the genome empowered logic scientific enthusiasm for finding their conceivable biological functions. microsatellite markers play a significant role in the guideline of transcription regulation, association of chromatin, the cell cycle and genome size (Li et al., 2004; Gao et al., 2013). Also, several reports indicated that microsatellites are common in various proteins and the frameworks engaged with their genesis may be related to the rapid evolution of proteins (Huntley and Golding, 2000; Katti et al., 2000). In this way, the aim of the current study was to utilize the microsatellite markers to estimate the genetic variations among five rabbit breeds in Egypt.

\section{MATERIALS AND METHODS}

\section{Ethical approval}

The experiment was carried out according to the National Regulations on Animal Welfare and Institutional Animal Ethics Committee.

\section{Animals}

The present experiment was conducted at the laboratory of biotechnology, Animal Production \& fish resources Department, Faculty of Agriculture, and the biotechnology research institute, Suez Canal University to identify the genetic variant between five rabbits' breeds in terms of detection of genetic diversity between New Zealand White (NZW, n=35), California ( $\mathrm{Cal}, \mathrm{n}=35$ ), Flander ( $\mathrm{F}, \mathrm{n}=19)$, Chinchilla (Ch, $\mathrm{n}=19)$, and Babion (B, $\mathrm{n}=20$ ), with a total number of 128 animals ranged between 19-35 animals per breed. 


\section{Blood samples and DNA extraction}

A total of 128 individual blood samples representing the five rabbit's breeds were randomly collected according to the institutional ethical norms of the Faculty of Agriculture, Suez Canal University, Egypt. About $1 \mathrm{ml}$ of blood from the marginal ear vein was individually collected in a tube treated with K3-EDTA (FL medical, Italy) and stored at $-20^{\circ} \mathrm{C}$ until DNA extraction. Genomic DNA was extracted using Quick-gDNA MiniPrep (Zymo Research, USA) to provide superior performance and high purity and yield of extracted DNA. The quality of extracted DNA was examined by NanoDrop® ND-1000 UV-Vis Spectrophotometer enabling highly accurate analyses with remarkable reproducibility.

\section{Selection of markers and genotyping}

Nine microsatellite markers within genes were selected (Table 1) according to Chantry-Darmon et al. (2005). To facilitate, all markers obtained were first tested on the rabbit's genomic DNA for polymorphism, then the PCR reactions were performed in a $25 \mu \mathrm{l}$ final volume containing $6 \mu 1$ of $100 \mathrm{ng}$ of DNA, $6 \mu \mathrm{l}$ of the PCR Super Mix contained 1.1x buffer (Invitrogen, 10572-014), forward and reverse primers $(0.2-1 \mathrm{uM}$ each), and nuclease-free $\mathrm{dH} 2 \mathrm{O}$ to final volume of 25 ul. An Eppendorf thermal cycler was used along with the following P CR profile settings: $5 \mathrm{~min}$ at $95^{\circ} \mathrm{C}$ followed by 35 cycles for $30 \mathrm{sec}$ at $95^{\circ} \mathrm{C}, 45 \mathrm{sec}$ at $53^{\circ} \mathrm{C}, 55^{\circ} \mathrm{C}, 57^{\circ} \mathrm{C}$ or $59^{\circ} \mathrm{C}$ annealing temperature, and $60 \mathrm{sec}$ at $72^{\circ} \mathrm{C}$, followed by an elongation step at $72^{\circ} \mathrm{C}$ for $10 \mathrm{~min}$, and finally stop step at $4^{\circ} \mathrm{C}$. Subsequently, PCR products were electrophoresed on $1.5 \%$ agarose gel containing $0.5 \%$ ethidium bromide which viewed under UV light.
Therefore, genotyping of the microsatellite markers was done using QIAxcel advanced system.

\section{Statistical analysis}

From the data observed from codominant markers, genetic diversity was assessed by calculating the observed ( $\mathrm{No}$ ), effective number of alleles $(\mathrm{Ne})$, the observed $(\mathrm{Ho})$ and the expected $(\mathrm{He})$ heterozygosity using GenAlEx 6.5 package (Peakall and Smouse, 2012). The Cervus 3.0.7 program (Kalinowski et al., 2007) was used to assess the polymorphism information content (PIC) according to the formula:

$$
\text { PIC }=1-\sum_{i=1}^{n} P_{i}^{2}-\sum_{i=1}^{n-1} \sum_{j=i+1}^{n} 2 P_{i}^{2} P_{j}^{2}
$$

where $P_{i}$ and $P_{j}$ are the frequencies of the $i^{\text {th }}$ and $j^{\text {th }}$ alleles at a locus with $l$ alleles in a population, respectively and $n$ was the number of alleles.

The F-statistics of pairwise genetic differentiation among the breeds $\left(F_{S T}\right)$, reduction in heterozygosity due to inbreeding for each locus $\left(F_{I T}\right)$ and the reduction in heterozygosity due to inbreeding within each breed $\left(F_{I S}\right)$ were obtained using AMOVA approach as implemented in GenAlEx 6.5. (Peakall \& Smouse, 2012). Additionally, deviation from Hardy-Weinberg equilibrium (HW) at each locus in each breed was tested was examined using GENEPOP program (Raymond and Rousset, 1995). To minimize the consequences of genotyping errors, those alleles found in only one type in at least two individuals were private ones. Genetic distances between breeds were calculated based on allelic frequencies (Nei, 1987) and a phylogenetic was constructed with the advantage of the PHYLIP package (Felsenstein, 1993).

Table 1. Characteristics of microsatellite markers used in the present study

\begin{tabular}{|c|c|c|c|c|c|c|}
\hline Locus & OCU & $\begin{array}{c}\text { Accession } \\
\text { number }\end{array}$ & $\begin{array}{c}\text { Associated } \\
\text { gene symbol }\end{array}$ & Gene description & $\begin{array}{c}\text { PCR } \\
\text { Temp }^{1} \\
\left({ }^{\circ} \mathbf{C}\right)\end{array}$ & Map position \\
\hline INRACCDDV0248 & 1 & AJ874579 & $\mathrm{PMCH}$ & Pro-melanin concentrating hormone & 57 & 1q15.1-q15.2 \\
\hline INRACCDDV0036 & 3 & AJ874398 & $\mathrm{CD} 14$ & Cyclin-dependent kinase inhibitor in the CIP/KIP family & 59 & 3 p21prox \\
\hline INRACCDDV0022 & 4 & AJ874385 & ERBB3 & Epidermal growth factor receptor3 & 59 & $4 \mathrm{q} 11$ \\
\hline INRACCDDV0211 & 5 & AJ874545 & HAS3 & Hyaluronan synthase 3 & 59 & $5 q 14$ \\
\hline INRACCDDV0221 & 7 & AJ874555 & GPR37 & G protein-coupled receptor 37 & 57 & $7 \mathrm{p} 21-\mathrm{p} 12$ \\
\hline INRACCDDV0304 & 10 & AJ874626 & EGFR & Epidermal growth factor receptor & 53 & 10q16ter \\
\hline INRACCDDV0241 & 14 & AJ874574 & TIAM1 & T cell lymphoma invasion and metastasis 1 & 55 & $14 \mathrm{q} 25$ \\
\hline INRACCDDV0031 & 17 & AJ874394 & $\mathrm{CAI} 2$ & Carbonic anhydrase 12 & 57 & $17 \mathrm{q} 11$ \\
\hline INRACCDDV0023 & 18 & AJ874386 & CYP2C18 & Cytochrome P450 family 2 subfamily $\mathrm{C}$ member 18 & 57 & $18 \mathrm{q} 31$ \\
\hline
\end{tabular}




\section{RESULTS AND DISCUSSION}

\section{Genetic markers polymorphism}

All microsatellite loci typed were polymorphic. The number of alleles per locus, polymorphic information content, expected and observed heterozygosity across all the breeds used are presented in table 2. A total of 97 alleles were detected across the breeds. The typical range of alleles per locus discovered over loci and breeds was $2.16 \pm 0.11$ alleles. The highest number was four alleles and was detected in INRACCDDV0023 and INRACCDDV0036 loci. However, the lowest number was two alleles and was detected in INRACCDDV0022 and INRACCDDV0221 loci. These findings were consistent with Tian-Wen et al. (2010) who reported the average number of alleles was 6.63 and ranged from 2.86 to 9.92 . Moreover, Xin-Sheng et al. (2008) found that the average number of alleles was 4.5 (ranged from 3 to 6 alleles) in Wan line Angora rabbits.

Interestingly, Grimal et al. (2012) found an average number of 5.41, ranged from 2 to 12 alleles, with the highest number for INRACCDDV0087 and the lowest for INRACCDDV0105. Also, El-Aksher et al. (2016) reported the average number of alleles for Moshtohor line rabbits was 6.75. Allele frequencies across microsatellite loci were different (Figure 5) that it was due to the differences in the distribution of the allele frequency for each allele size among the breeds. The highest allele frequency was 0.846 for the INRACCDDV0023 with the allele sizes of 211 bp in Chinchilla. The highest allele frequency in NZW and Flander rabbits was 0.842 and 0.763 for INRACCDDV0211 marker with the allele size of $206 \mathrm{bp}$, respectively. Moreover, the highest allele frequency in California breed was 0.757 for the INRACCDDV0304 marker with allele size of $304 \mathrm{bp}$ (Figure 1).

Finally, the Babion rabbits have the highest allele frequency as 0.50 for the markers INRACCDDV0221 and INRACCDDV0241 with allele sizes of $117 \mathrm{bp}$ and $150 \mathrm{bp}$, respectively. These results are in line with Xin-Sheng et al. (2008) who revealed that allele frequencies ranged from 0.98 to 0.412 for SOL44 marker, and from 0.049 to 0.48 for SAT13 marker.

\section{Genetic relationships among rabbit genotypes}

The results indicated that the Chinchilla breed is distinctive from other breeds (Figure 2). Interestingly, the equality of both California and NZW is presented (Table 3). Galal et al. (2013) concluded that there was a low genetic variation within each of the four rabbit genotypes (APRI line, NZW, Baladi Black, and Gabali breeds) based on biochemical markers. In order to evaluate the genetic variation within breeds, total number of alleles, number of alleles per locus, private alleles, expected heterozygosity (He, estimated by Nei, 1978) and observed heterozygosity (Ho) have calculated.

\section{Observed and expected heterozygosity across breeds}

The observed $(\mathrm{Ho})$ and expected $(\mathrm{He})$ heterozygosity and the polymorphic information content (PIC) for each marker over the examined breeds are displayed in table 2 . The wide parameters used to measure the genetic diversity across and within the populations is $\mathrm{He}$ or the gene diversity as defined by Nei (1973). The $\mathrm{Ho}$ in all microsatellite markers was higher than $\mathrm{He}$ at all rabbits' breeds. The means of $\mathrm{He}$ values were ranged from $0.35 \pm 0.06$ to $0.49 \pm 0.07$. The $H o$ for different markers averaged $0.58 \pm 0.05$ and ranged from 0.06 (INRACCDDV0022) to 0.99 (INRACCDDV0036). The overall mean of $\mathrm{He}$ was $0.422 \pm 0.03$ and ranged from 0.37 at INRACCDDV0211 to 0.66 at INRACCDDV0036. These results in full agreement with Ben Larbi et al. (2014) who realized that $\mathrm{Ho}$ ranged from 0.3 to 0.53 across 36 loci used in twelve rabbit populations. The distinguished results might be due to the number of markers and/or the number of populations that used. Similarly, to the obtained results, Xin-Sheng et al. (2008) found that the highest heterozygosity was 0.721 at locus SOL33, and the lowest level of heterozygosity was 0.63 when different markers were used.

From this point, it was clear that although the microsatellites used were different from other studies, the obtained heterozygosity values were closed. The PIC might be used to ascertain the heterozygosity and the alleles' numeral in the population. The PIC average is 0.41 with the values ranging from 0.298 at locus INRACCDDV0211 to 0.599 at locus INRACCDDV0036. These values were dissimilar with those of Schwartz et al. (2007) who found the lowest PIC was 0.27 at locus SOL33 and the highest PIC value was 0.70 at locus SAT16.

Similarly, Xin-Sheng et al. (2008) found the PIC average was 0.642 (ranged from 0.559 to 0.705 ). Moreover, another range of PIC (0.60 - 0.86) was obtained by El-Aksher et al. (2016). Accordingly, the microsatellite markers that utilized could propose their adequacy in the linkage mapping programs and genetic polymorphism studies in rabbits (Schwartz et al., 2007; Hongmei et al., 2008; Tian-Wen et al., 2010). 
Table 2. Variability parameters for the microsatellite markers

\begin{tabular}{lccccccccccc}
\hline Locus & $\mathbf{N a}$ & $\mathbf{N e}$ & $\mathbf{I}$ & $\boldsymbol{H o}$ & $\boldsymbol{H e}$ & $\mathbf{N m}$ & $\boldsymbol{F}$ & $\boldsymbol{F}_{\boldsymbol{S T}}$ & $\boldsymbol{F}_{\boldsymbol{I S}}$ & $\boldsymbol{F}_{\boldsymbol{I T}}$ & $\boldsymbol{P I C}$ \\
\hline INRACCDDV0022 & 0.80 & 0.79 & 0.27 & 0.02 & 0.20 & 0.068 & 0.92 & 0.785 & 0.922 & 0.983 & 0.372 \\
INRACCDDV0248 & 2.80 & 2.58 & 0.98 & 0.88 & 0.61 & 7.469 & -0.47 & 0.032 & -0.448 & -0.401 & 0.560 \\
INRACCDDV0023 & 2.20 & 1.75 & 0.63 & 0.53 & 0.40 & 0.737 & -0.32 & 0.253 & -0.329 & 0.008 & 0.421 \\
INRACCDDV0221 & 2.00 & 1.73 & 0.61 & 0.64 & 0.42 & 5.096 & -0.51 & 0.047 & -0.546 & -0.474 & 0.319 \\
INRACCDDV0036 & 3.20 & 2.90 & 1.10 & 0.99 & 0.65 & 8.508 & -0.54 & 0.029 & -0.536 & -0.493 & 0.599 \\
INRACCDDV0211 & 2.00 & 1.63 & 0.56 & 0.56 & 0.38 & 3.431 & -0.44 & 0.068 & -0.491 & -0.390 & 0.298 \\
INRACCDDV0031 & 2.00 & 1.48 & 0.51 & 0.41 & 0.32 & 0.712 & -0.26 & 0.260 & -0.258 & 0.069 & 0.335 \\
INRACCDDV0304 & 2.20 & 1.80 & 0.65 & 0.58 & 0.42 & 1.440 & -0.37 & 0.148 & -0.402 & -0.195 & 0.406 \\
INRACCDDV0241 & 2.20 & 1.79 & 0.65 & 0.58 & 0.42 & 4.402 & -0.37 & 0.054 & -0.407 & -0.331 & 0.364 \\
Overall mean \pm SE & $2.16 \pm 0.11$ & $1.83 \pm 0.11$ & $0.66 \pm 0.04$ & $0.58 \pm 0.05$ & $0.42 \pm 0.03$ & $3.541 \pm 1.025$ & $-0.35 \pm 0.05$ & $0.186 \pm 0.081$ & $-0.277 \pm 0.153$ & $-0.136 \pm 0.155$ & 0.408
\end{tabular}

Na: Number of different alleles, Ne: Number of effective alleles, I: Shannon's information index, $H e$ : expected heterozygosity. $H o$ : observed heterozygosity, $F_{I S}$ : heterozygosis deficit, $F_{S T}$ : population variation, $F_{I T}$ : heterozygosity due to inbreeding, Nm: Gene flow, F: Fixation index, PIC: Polymorphic information content, SE: Standard error.
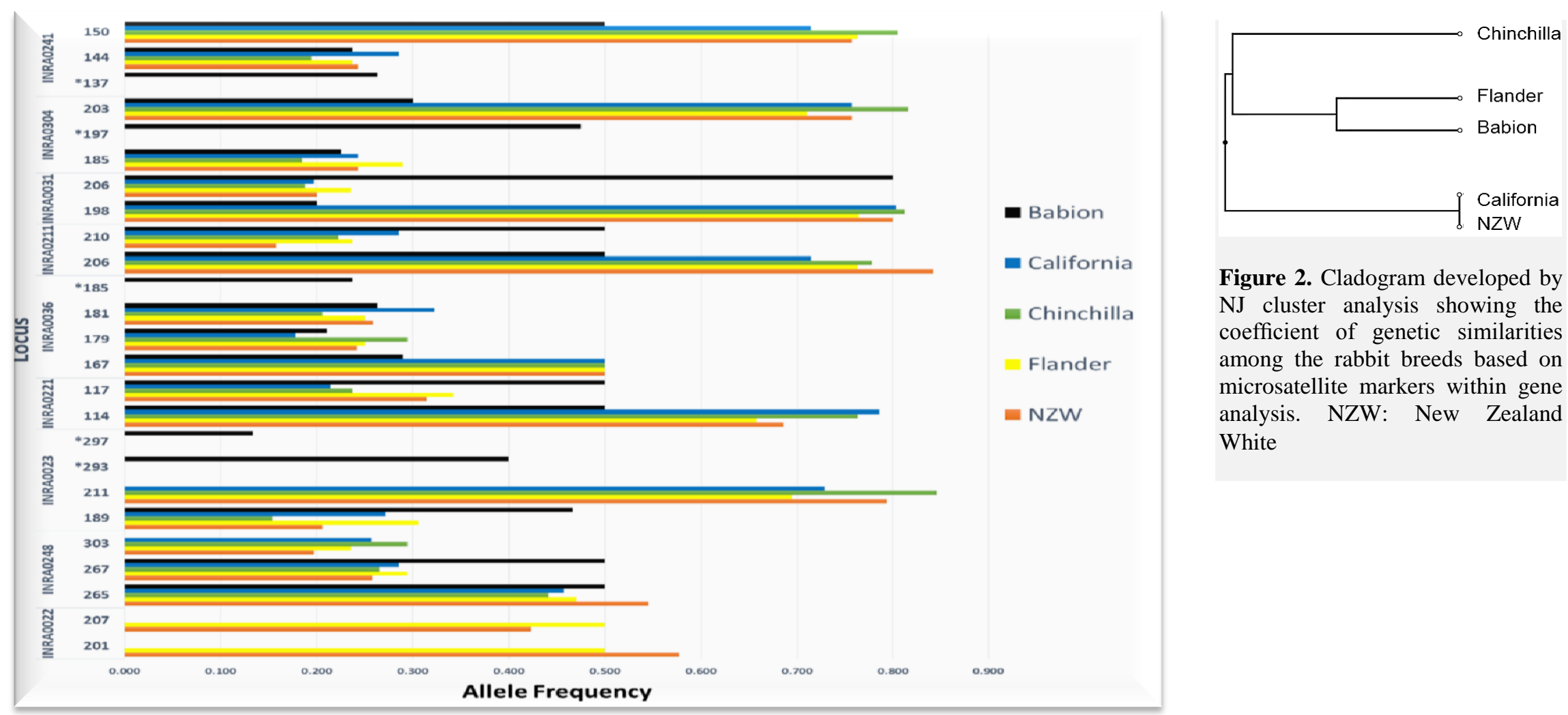

Figure 2. Cladogram developed by NJ cluster analysis showing the coefficient of genetic similarities among the rabbit breeds based on microsatellite markers within gene analysis. NZW: New Zealand White

Figure 1. The allelic size and allele frequency per locus for each rabbit breed. *Private allele; NZW: New Zealand White 
Table 3. Genetic distances among the different rabbit breeds

\begin{tabular}{l|c|c|c|c|c}
\hline Rabbit breeds & Chinchilla & $\begin{array}{c}\text { New Zealand } \\
\text { White }\end{array}$ & Babion & Flander & California \\
\hline Chinchilla & 0 & 0.235 & 0.5 & 0.529 & 0.235 \\
\hline $\begin{array}{l}\text { New Zealand } \\
\text { White }\end{array}$ & & 0 & 0.382 & 0.353 & 0 \\
\hline Babion & & & 0 & 0.265 & 0.382 \\
\hline Flander & & & & 0 & 0.353 \\
\hline California & & & & & 0 \\
\hline
\end{tabular}

\section{Hardy-Weinberg Equilibrium and private alleles} over the studied breeds

Among the nine loci, the Hardy-Weinberg equilibrium (HW) was highly significant differentiated $(P \geq 0.001)$ for five loci, but not significant with four loci (Table 4). Although, INRACCDDV0241 locus was highly significant for Babion, it was not significant for NZW, Flander, and Chinchilla. Instead, the INRACCDDV0022 locus was highly significant in NZW, it was significant in Chinchilla, California, and Babion breeds (Table 4). Moreover, all the microsatellite loci in this examination were polymorphic, showing that the loci were appropriate for the genetic investigation of lab rabbits in Egypt. Private alleles were likewise present in five alleles and were realized in Babion breed (Figure 3). The locus INRACCDDV0023 had two private alleles at 293 and 297 bp with allele frequency 0.4 (freq: 0.4 ), and 0.1 respectively. The locus INRACCDDV0036, INRACCDDV0304, and INRACCDDV0241 had private allele for each (185 bp (freq: 0.24), 197 (freq: 0.47), and 137 bp (freq: 0.26), respectively (Figures 1 and 3). In contrast, Grimal et al. (2012) did not reach any private allele for the locus INRACCDDV0241 with four Egyptian breeds and Spanish New Zealand White breed. Increasing the numbers of individuals sampled has two effects, one is to increase the integer of private alleles in the samples, thereby increasing the accuracy of the evaluations of gene flow (Slatkin, 1985).

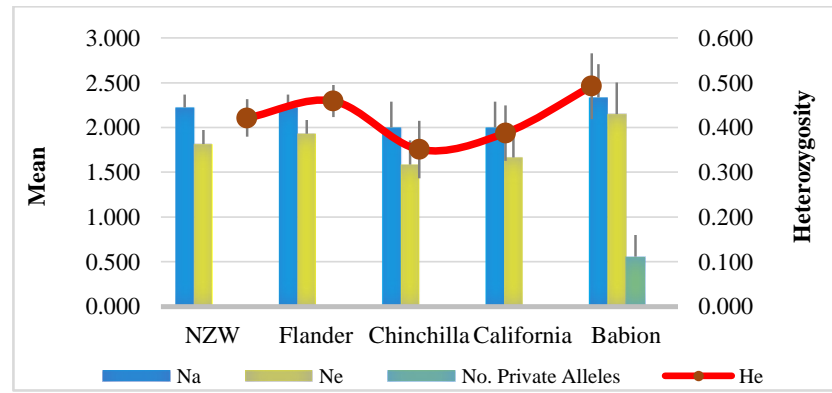

Figure 3. Allelic patterns across five rabbit breeds. Na: number of different alleles, Ne: number of effective alleles, No: number of private alleles, and He: Expected heterozygosity. NZW: New Zealand White

\section{Genetic Variation and breeds diversity}

To estimate the genetic variation of the five rabbit' breeds, genetic differentiation $\left(F_{S T}\right)$, and genetic distance were evaluated. The negative $F_{I S}$ values observed for all studied locus except the INRACCDDV0022 locus (Table 2 ) as Tian-Wen et al. (2010) when observed negative $F_{I S}$ values. Contradictory, El-Aksher et al. (2016) attained the $F_{I S}$ with positive values but were closed to zero which indicated low inbreeding within the population. In addition, the negative $F_{I S}$ values would reflect random sampling error or the individual has fewer homozygotes than one would expect by chance at the genome-wide level. The values of $F_{S T}$ for the nine loci are shown in table 2. The $F_{S T}$ values fluctuated from 0.029 (INRACCDDV0036) to 0.785 (INRACCDDV0022).

Other reports showed that the emphatically low $F_{S T}$ (0.0137 and 0.099) (Grimal et al., 2012; Tian-Wen et al., 2010). Additionally, $F_{S T}$ comparisons from entirely unexpected components of the genome will offer bits of knowledge into the demographic history of populations (Holsinger and Weir, 2009). Shannon's Information index (I) averaged 0.66 and ranged between 0.27 (INRACCDDV0022) to 1.1 (INRACCDDV0036). This record is a proportion of strength and it is the likelihood that two individuals randomly represented from an infinitely population will be different species. In addition, Simpson's Index is usually expressed as the reciprocal, so the higher values represent higher diversity which was indorsed by the patterns of the neighbor-joining phylogenetic tree (Figure 4). Moreover, the genetic diversity within individuals $(78 \%)$ and among breeds $(22 \%)$ was highly significant (Table 5). In addition, gene flow $(\mathrm{Nm})$ ranged from 0.068 at INRACCDDV0022 to 8.508 at INRACCDDV0036 and averaged 3.541. Slatkin (1985) counted that if the value of $\mathrm{Nm}>1$, the quality trade among populace can avert the effect of genetic drift and diminish the genetic divergence among populaces. In the current study, the obtained $\mathrm{Nm}$ was indicating that the gene flow was one of the significant variables impacting the genetic construction of rabbits' populations. The moderately high gene flow likely averts genetic distinctions, which is the purpose behind the watched low genetic differences. That is the motivation behind why the difference within individuals was higher than that among breeds. Along these, the absence of differentiation between many breeds such as NZW and California is credited to gene flow.

It can be expected that gene flow would be constrained, and that reasonable level of genetic structure would be obvious among test from individuals selected from the area isolated by obstructions and separations more than a few kilometers. Be that as it may, investigations dependent on 9 microsatellite loci from 128 rabbits uncovered all chromosomes, therefore this study assumed to be in low to adequate level of genetic diversity as demonstrated by Estes-Zumpf et al. (2010). A past report brief that microsatellite markers utilized in investigations of genetic variation and distances should don't have any less than four alleles in order to curtail the standard errors of estimated distances (Barker, 1994) and that such microsatellite markers should have a $\mathrm{Ho}$ of somewhere in the range of 0.3 and 0.8 inside the population (Takezaki and Nei, 1996). 
Table 4. Results of Chi-Square test for Hardy-Weinberg equilibrium

\begin{tabular}{|c|c|c|c|c|c|c|c|c|c|c|c|c|c|c|c|c|c|}
\hline \multirow{2}{*}{ Locus } & \multirow{2}{*}{$d f$} & \multicolumn{3}{|c|}{ New Zealand White } & \multicolumn{3}{|c|}{ Flander } & \multicolumn{3}{|c|}{ Chinchilla } & \multicolumn{3}{|c|}{ California } & \multicolumn{3}{|c|}{ Babion } & \multirow{2}{*}{$\begin{array}{l}\text { Hardy-Weinberg } \\
\text { Equilibrium for } \\
\text { locus over breed }\end{array}$} \\
\hline & & ChiSq & Prob & Sig & ChiSq & Prob & Sig & ChiSq & Prob & Sig & ChiSq & Prob & Sig & ChiSq & Prob & Sig & \\
\hline INRACCDDV0022 & 1 & 18.45 & 0.00 & $* * *$ & 8.00 & 0.00 & $* *$ & M & - & - & M & - & - & M & - & - & $* * *$ \\
\hline INRACCDDV0248 & 3 & 12.07 & 0.01 & $* *$ & 5.58 & 0.13 & NS & 4.71 & 0.19 & NS & 9.90 & 0.02 & $*$ & M & - & - & $* * *$ \\
\hline INRACCDDV0023 & 1 & 2.29 & 0.13 & NS & 3.48 & 0.06 & NS & 0.43 & 0.51 & NS & 4.86 & 0.03 & $*$ & 3.00 & 0.01 & $*$ & NS \\
\hline INRACCDDV0221 & 1 & 7.35 & 0.01 & $* *$ & 5.14 & 0.02 & $*$ & 1.83 & 0.18 & NS & 2.60 & 0.11 & NS & M & - & - & $* *$ \\
\hline INRACCDDV0036 & 3 & 21.69 & 0.00 & $* * *$ & 12.00 & 0.01 & $* *$ & 17.00 & 0.00 & $* * *$ & 31.00 & 0.00 & $* * *$ & 6.00 & 0.00 & $* *$ & $* * *$ \\
\hline INRACCDDV0211 & 1 & 0.67 & 0.41 & $\mathrm{NS}$ & 1.83 & 0.18 & NS & 1.47 & 0.23 & NS & 5.60 & 0.02 & $*$ & M & - & - & NS \\
\hline INRACCDDV0031 & 1 & 1.88 & 0.17 & NS & 1.61 & 0.20 & NS & 0.85 & 0.36 & NS & 1.99 & 0.16 & NS & 1.25 & 0.26 & NS & NS \\
\hline INRACCDDV0304 & 1 & 3.60 & 0.06 & NS & 3.15 & 0.08 & NS & 0.97 & 0.32 & NS & 3.60 & 0.06 & NS & 20.00 & 0.00 & $* * *$ & NS \\
\hline INRACCDDV0241 & 1 & 3.60 & 0.06 & NS & 1.83 & 0.18 & NS & 1.05 & 0.31 & NS & 5.60 & 0.02 & $*$ & 19.00 & 0.00 & $* * *$ & $* * *$ \\
\hline
\end{tabular}

Prob: Probability, ChiSq: Chi-Square, M: Monomorphic, NS: Not significant, $\boldsymbol{d f}$ : Degree of freedom, Sig: Significant $\left({ }^{*} \mathrm{p} \leq 0.05,{ }^{* *} \mathrm{p} \leq 0.01,{ }^{* * *} \mathrm{p} \leq 0.001\right)$

Table 5. Analysis of molecular variance in studied generations

\begin{tabular}{lccccccc}
\hline Source & $\boldsymbol{d f}$ & $\boldsymbol{S S}$ & $\boldsymbol{M S}$ & Est. Var. & $\boldsymbol{\%}$ & F-statistic & p-value \\
\hline Among breeds & 4 & 127.420 & 31.855 & 0.598 & 22 & 0.226 & 0.001 \\
Among individuals & 123 & 239.299 & 1.946 & 0.000 & 0 & -0.051 & 0.960 \\
Within individuals & 128 & 276.000 & 2.156 & 2.156 & 78 & 0.186 & 0.001 \\
Total & 255 & 642.719 & -- & 2.754 & 100 & -- & -- \\
\hline
\end{tabular}

$\overline{d f:}$ degrees of freedom, $S S$ : sum of squares, $M S:$ mean square, Est. Var: Estimated variance. 


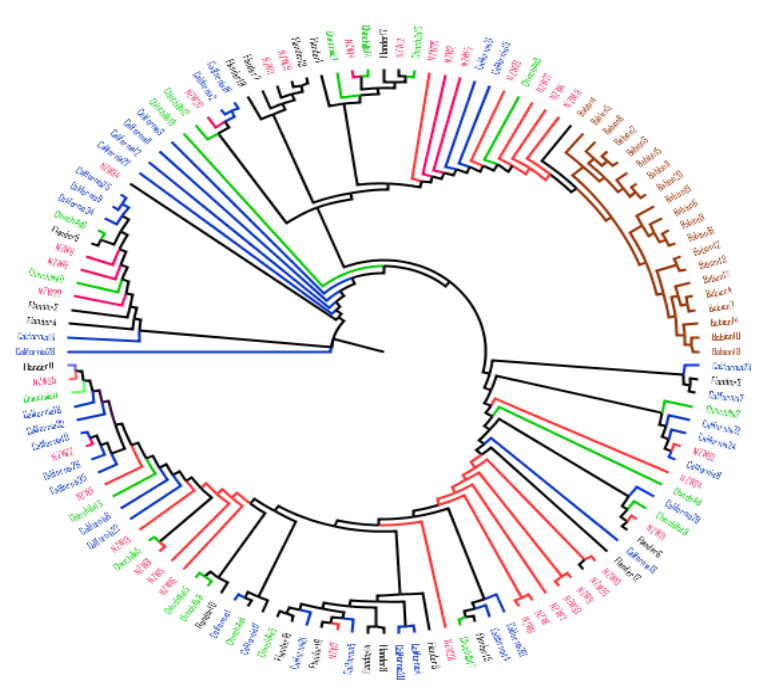

$\overline{4.0}$

Figure 4. Neighbor-Joining phylogenetic tree based on allele sharing distance for 128 rabbits from different breeds. New Zealand White (red), California (blue), Flander (black), Chinchilla (green), and Babion (brown).

\section{CONCLUSION}

One of the main points of the current study was to interpret patterns of differentiation among microsatellite loci taking into account their genome location. The highest number of alleles was identified in INRACCDDV0023 and INRACCDDV0036 loci, which they had two and one private alleles, respectively, located at map position of $18 \mathrm{q} 31$ and 3p21prox. Moreover, on chromosome 4 the INRACCDDV0022 locus was highly significant deviated from Hardy-Weinberg equilibrium in New Zealand White breed, but it was not in Chinchilla, California, and Babion breeds. It is essential to note, sampling of loci was not dense enough to recognize all separated chromosome regions or to affirm that the identified alleles of high polymorphic loci did not represent multiple independent information. It is suggested to address these concerns by scanning the genome with a much higher density of markers. Finally, this study emphasized the necessity of biodiversity inquires in rabbits to characterize complex patterns.

\section{DECLARATION}

\section{Acknowledgments}

The support of the Department of Animal Production and Fish Resources, Faculty of Agriculture, Suez Canal University, Ismailia, Egypt, are gratefully acknowledged.

\section{Conflict of interest}

There is no conflict of interest.

\section{REFERENCES}

Badr OA, EL-Shawaf IIS, Khalil MH, Refaat MH and El-Zarei MF (2016). Assessment of genetic variability among some rabbit breeds using RAPD-DNA technique. 3rd International Conference on Biotechnology Applications in Agriculture (ICBAA), Benha University, Moshtohor and Sharm El-Sheikh, Egypt. pp. 1-8. Available at:https://www.researchgate.net/publication/327727936

Barker JSF (1994). A global protocol for determining genetic distance among domestic livestock breeds. Proceeding of $5^{\text {th }}$ World Congress on Genetics Applied to Livestock Production, Guelph, Canada, 21: 501-508. Available at: http://www.wcgalp.org/system/files/proceedings/1994/globalprotocol-determining-genetic-distances-among-domestic-livestockbreeds.pdf

Ben Larbi M, San-Cristobal M, Chantry-Darmon C and Bolet G (2014). Population structure in Tunisian indigenous rabbit ascertained using molecular information. World Rabbit Science, 22: 223-230. DOI:10.4995/wrs.2014.1468

Chantry-Darmon C, Urien C, De Rochambeau H, Allain D, Pena B and Hayes H (2006). A first-generation microsatellite-based integrated genetic and cytogenetic map for the European rabbit (Oryctolagus cuniculus) and localization of angora and albino. Animal Genetics, 37:309-431. DOI:10.1111/j.1365-2052.2006.01462.x

El-Aksher SH, Sherif HS, Khalil MH, El-Garhy HAS and Ramadan S (2017). Molecular analysis of a new synthetic rabbit line and their parental populations using microsatellite and SNP markers. Gene Reports, 8:17-23. DOI:10.1016/j.genrep.2017.05.001

El-Aksher SH, Sherif HS, Khalil MH, El-Garhy HAS and Ramadan S (2016). Comparative genetic analysis among Moshtohor line rabbits and their parental lines using microsatellite markers. 3rd International Conference on Biotechnology Applications in Agriculture (ICBAA), Benha University, Moshtohor and Sharm ElSheikh, $\quad$ Egypt. $\quad$ pp.7-24 Available at:https://www.researchgate.net/publication/301199268

Estes-Zumpf WA, Rachlow JL, Waits LP, and Arheit KEIW (2010). Dispersal, gene flow, and population genetic structure in the pygmy rabbit (Brachylagus idahoensis) Journal of Mammalogy, 91:208-219, DOI: 10.1644/09-MAMM-A-032R.1.

Felsenstein J (1993). PHYLIP (Phylogeny Inference Package) version 3.5c. Distributed by the author. Department of Genetics, University of Washington, Seattle. Available at:http://www.nih.go.jp/ jun/research/phylip/main.html?ref=hersey bedava.info

Galal OA, Rehan M and Abd El-Karim RE (2013). Analysis of genetic diversity within and among four rabbit genotypes using biochemical and molecular genetic markers. African Journal of Biotechnology, 2830-2839. DOI:10.5897/AJB2013.12332

Gao C, Ren X, Mason AS, Li J,Wang W, Xiao M and Fu D (2013). Revisiting an important component of plant genomes: microsatellites. Functional Plant Biology, 40:645. DOI: 10.1071/FP12325

Grimal A, Safaa HM, Saenz-deJuano MD, Viudes-de-Castro, MP, Mehaisen GMK, Elsayed DAA, Lavara R, Marco-Jiménez F and Vicente JS (2012). Phylogenetic relationship among four Egyptian andone Spanish rabbit populations based on microsatellite markers. World Rabbit Congress, Sharm El- Sheikh, Egypt, 177-181. Available at:https://www.researchgate.net/publication/258994667

Holsinger KE and Weir BS (2009). Genetics in geographically structured populations: defining, estimating and interpreting FST. Nature Reviews Genetics, 10: 639-650. DOI:10.1038/nrg2611

Hongmei S, Xiumei X, Min R and Bo C (2008). Genetic diversity and phylogenetic relationship of rabbit breeds based on microsatellite 
Rabie, 2020

DNA markers. Biodiversity Science, 16: 492-497. DOI:10.3724/SP.J.1003.2008.08051

Huntley M and Golding GB (2000). Evolution of simple sequence in proteins. Journal of Molecular Evolution, 51:131-140. DOI: $10.1007 / \mathrm{s} 002390010073$

Kalinowski ST, Taper ML and Marshall TC (2007). Revising how the computer program CERVUS accommodates genotyping error increases success in paternity assignment. Molecular Ecology, 16:1099-1106. DOI:10.1111/j.1365-294X.2007.03089.x

Katti MV, Sami-Subbu R, Ranjekar PK and Gupta VS (2000). Amino acid repeat patterns in protein sequences: Their diversity and structural-functional implications. Protein Science, 9:1203-1209. DOI: $10.1110 /$ ps.9.6.1203

Korstanje R (2000). Development of a genetic and comparative map of the rabbit. A tool for QTL mapping (Ph.D. dissertation). Utrecht, The Netherlands: Utrecht University.

Korstanje R, Gillissen GF, den Bieman MG, Versteeg SA, vanOost B, Fox RR, van Lith HA and van Zutphen LF (2001). Mapping of rabbit chromosome 1 markers generated from a microsatelliteenriched chromosome-specific library. Animal Genetics, 32: 30812. DOI:10.1046/j.1365-2052.2001.00783.x

Korstanje R, Gillissen GF, Versteeg SA, van Oost BA, Bosma AA, Rogel-Gaillard C, van Zutphen LF and Van Lith HA (2003). Mapping of rabbit microsatellite markers using chromosome specific libraries. Journal of Heredity, 94:161-9. DOI: 10.1093/jhered/esg016

Li Y-C, Korol AB, Fahima T and Nevo E (2004). Microsatellites within genes: structure, function, and evolution. Molecular Biology and Evolution, 21:991-1007. DOI:10.1093/molbev/msh073

Nei M (1973). Analysis of gene diversity in subdivided populations. Proceedings of the National Academy of Sciences, USA 70: 33213323. DOI:10.1073/pnas.70.12.3321

Nei M (1978). Estimation of average heterozygosity and genetic distance from a small number of individuals. Genetics, 89:583-590. PMID: 17248844
Nei M (1987). Molecular Evolutionary Genetics. Columbia University Press, New York, NY. DOI:10.1002/ajpa.1330750317

Peakall R and Smouse PE (2012). GenAlEx 6.5: genetic analysis in Excel. Population genetic software for teaching and research - an update. Bioinformatics, 28: 2537-2539. DOI: 10.1093/bioinformatics/bts460

Rabie TSKM (2012). Inter- and intra- breeds divergence in rabbits using of SDS-PAGE for liver Protein. 3rd Medetranian poultry summit and $6^{\text {th }}$ International conference for poultry sciences, Book of Proceedings, 1752-1763. Available at: https://www.researchgate.net/publication/265376908

Raymond M and Rousset F (1995). GENEPOP (v 1.2): population genetics software for exact tests and ecumenicism. Journal of Heredity, 86: 248-249. DOI:10.1093/oxfordjournals.jhered.a111573

Schwartz MK, Pilgrim KL, McKelvey KS, Rivera PT and Ruggiero LF (2007). DNA markers for identifying individual snowshoe hares using field collected pellets. Northwest Science, 81: 316322. DOI:10.3955/0029-344X-81.4.316

Slatkin M (1985). Rare alleles as indicators of gene flow. Evolution, 39:53-65. DOI: 10.1111/j.1558-5646.1985.tb04079.x

Takezaki N and Nei M (1996). Genetic distance and reconstruction of phylogenetic trees from microsatellite DNA. Genetics, 144: 389399

Tian-Wen W, Gui-Jiang X, Yu-Laip, Xi-Ping X, Bi-Chun L and XinSheng W (2010). study on genetic diversity of 7 rabbit populations evidenced by microsatellite markers. Journal of Animal and Veterinary Advances, 9: 395-365. DOI:10.3923/javaa.2010.359.365

Xin-Sheng W, Tian-Wen W, Hui-ling Z, long CG, Qi X, Jin-Hua C, Zhu Xiu-Bai Z and Guo-Hong C (2008). Correlation analysis of wool yield in Wan line Angora rabbits using microsatellite DNA markers. Journal of Biological Sciences, 8: 679-682. DOI:10.3923/jbs.2008.679.682 